DOI: $10.15593 / 24111678 / 2018.01 .08$

УДК $625.855 .3: 539.389 .3$

\author{
М.Г. Салихов ${ }^{1}$, В.Ю. Иливанов ${ }^{2}$, Л.И. Малянова ${ }^{3}$, Е.В. Веюков ${ }^{1}$ \\ ${ }^{1}$ Поволжский государственный технологический университет, Йошкар-Ола, Россия \\ ${ }^{2}$ Чувашский государственный университет им. И.Н. Ульянова, Чебоксары, Россия \\ ${ }^{3}$ Волжский филиал Московского государственного технического университета (МАДИ), \\ Чебоксары, Россия

\section{ИЗУЧЕНИЕ ТЕМПЕРАТУРНОГО СТАРЕНИЯ МОДИФИЦИРОВАННОГО ЩЕБЕНОЧНО-МАСТИЧНОГО АСФАЛЬТОБЕТОНА С ОТХОДАМИ ДРОБЛЕНИЯ ИЗВЕСТНЯКОВ}

\begin{abstract}
Приведены результаты экспериментального исследования свойств образцов не модифицированного и модифицированного щебеночно-мастичного асфальтобетона и асфальтобетона с отходами дробления известняков типа Б. Изучена динамика изменения значений пределов прочности при сжатии образцов асфальтобетонов при $+20,+50{ }^{\circ} \mathrm{C}$ и в водонасыщенном состоянии, коэффициента водостойкости, трещиностойкости, сдвигоустойчивости по коэффициенту внутреннего трения и по сцеплению при сдвиге при температуре $50{ }^{\circ} \mathrm{C}$, МПа, сформованных из смесей после предварительного прогревания при температуре $(+150 \pm 2){ }^{\circ} \mathrm{C}$ в течение $0,1,3,5,6,7$ ч. На основе выполненных экспериментов установлено, что при введении в составы асфальтобетонных смесей небольшого количества кубовых остатков при производстве 8ПФДА и анилина (от 0,5 до 1,2\% от массы битума) повышается сцепление битума с минеральными составляющими, увеличивается их сопротивляемость старению при выдерживании в высоких температурах и т.д. Исследования старения выполнены по предложенной авторами методике - при помощи безразмерного коэффициента старения. Такой подход позволяет при анализе динамики изменения свойств изучаемых образцов асфальтобетонов под воздействием высоких температур (старении) использовать имеющееся в строительных лабораториях стандартное лабораторное оборудование и освободиться от влияния на конечный результат исследований масштабного фактора. Выбор заданного значения температуры предварительного прогревания смеси был обусловлен тем, что рабочие температуры приготовления горячих смесей с использованием битума БНД 90/130 находятся в пределах $140-160{ }^{\circ} \mathrm{C}$. Конечная продолжительность прогревания смесей принята равной 5-7 ч, когда скорость (интенсивность) изменения численных значений показателей свойств стабилизируется.
\end{abstract}

Ключевые слова: щебеночно-мастичный асфальтобетон, отходы дробления известняков, асфальтобетон типа Б, высокая температура, старение.

\author{
M.G. Salichov ${ }^{1}$, V.J. Ilivanov ${ }^{2}$, L.I. Malyanova ${ }^{3}$, E.V. Veyukov ${ }^{1}$ \\ ${ }^{1}$ Volga State University of Technology, Yoshkar-Ola, Russian Federation \\ ${ }^{2}$ Chuvash State University named after I.N. Ulyanov, Cheboksary, Russian Federation \\ ${ }^{3}$ Volga Branch of Moscow State Automobile and Road Technical University, \\ Cheboksary, Russian Federation
}

\title{
INVESTIGATION OF THERMAL AGING OF MODIFIED STONE MASTIC ASPHALT CONCRETE WASTE CRUSHING LIMESTONE
}

The results of experimental studies of the properties of samples unmodified and modified stone mastic asphalt and asphalt concrete waste crushing limestone type B. Set the dynamics of changes in values of ultimate strength in compression at $+20,+50{ }^{\circ} \mathrm{C}$ and in saturated condition, the coefficient of water resistance, fracture toughness, coefficient of internal friction and clutch pre-heating of the mixtures at a temperature of $150 \pm 2{ }^{\circ} \mathrm{C}$ for $0,1,3,5,6,7$ hours. Based on the experiments reveals the mechanism occurring physico-mechanical processes in the structure modified with small additions of distillation residues

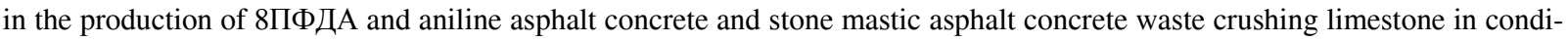
tions finding at high temperatures, the number of which varied from 0 to $3.0 \%$ by weight of the bitumen (BND 90/130). The optimal amount of modifying additives is 0.5 to 1.0 percent. The studies were performed on the proposed method using the dimensionless coefficient of aging. This approach allows the study of the dynamics of changes in the properties of test samples of asphalt concrete subjected to high temperatures (aging) use the existing construction laboratories standard laboratory equipment and be free from the influence on the final result of the research of scale factor. The choice of the set value of tem- 
perature of preliminary heating of the mixture was due to the fact that operating temperatures of the hot mixes using bitumen BND 90/130 are in the range of $140 \ldots 160{ }^{\circ} \mathrm{C}$.The ultimate duration of the warm up mix taken $5-7$ hours, when the speed (intensity) changes of properties stabiliziruemost.

Keywords: stone mastic asphalt, waste crushing limestone, asphalt type B, high temperature, aging.

Щебеночно-мастичные асфальтобетоны в настоящее время на высоконагруженных дорогах являются одним из основных конструкционных материалов для верхнего слоя покрытий благодаря хорошим эксплуатационным качествам и сравнительной долговечности. Однако они гораздо дороже традиционно используемых асфальтобетонных составов, отвечающих по своим свойствам требованиям ГОСТ 9128-2013. Принимая это во внимание, в Поволжском государственном технологическом университете изобретены новые материалы - модифицированный асфальтобетон и щебеночно-мастичный асфальтобетон (ЩМА) с отходами дробления известняков (ОДИ), использование которых обеспечивает сравнительно меньшую стоимость и расход вяжущего [1-6]. Составы исследованных образцов асфальтобетонов следующие:

1. Известный (классический) состав асфальтобетона типа Б по ГОСТ 9128-2013: щебень прочный М 1200 фр. 5...20 - 47,0 \%; отсевы дробления прочных пород (дробленый песок) 43,0 \%; известняковый минеральный порошок - 10,0 \%; битум нефтяной вязкий БНД 90/130 $5,5 \%$ (сверх $100 \%$ от массы минеральной части).

2. Не модифицированный асфальтобетон с ОДИ типа Б: щебень прочный М 1200 фр. 5...20 - 47,0 \%; отсевы дробления прочных пород (дробленый песок) - 43,0 \%; отходы дробления известняков - 10,0 \%; битум нефтяной вязкий БНД 90/130 - 5,5 \% (сверх $100 \%$ от массы минеральной части).

3. Модифицированный асфальтобетон с ОДИ типа Б: щебень прочный М 1200 фр. 5..20 мм - 47,0 \%; отсевы дробления прочных пород (дробленый песок) - 43,0 \%;отходы дробления известняков - 10,0 \%; битум нефтяной вязкий БНД 90/130 - 5,0 \% (сверх $100 \%$ от массы минеральной части); модифицирующая добавка - 0...3,0 \% (от массы битума).

4. Модифицированный ЩМА с ОДИ: щебень прочный М 1200 фр. 5...20 мм - 73,0 \%; отходы дробления известняков - 27,0 \%; битум нефтяной вязкий БНД 90/130 - 5,8 \% (сверх $100 \%$ от массы минеральной части); модифицирующая добавка - 0...3,0 \% (от массы битума).

В качестве модифицирующих добавок в них используются кубовые остатки при производстве продукта «Новантокс 8 ПФДА» или анилина (АсД), являющиеся отходами Новочебоксарского химического завода Чувашской Республики.

Кубовые остатки при производстве анилина (АсД) состоят (мас. \%): из анилина - 40,00 \%; циклогексиламина $-0 \ldots 10 \%$; дефиламина $-0,45 \%$. Они образуются в процессе выделения целевого продукта - анилина, и при $+20{ }^{\circ} \mathrm{C}$ с высоким содержанием анилина представляет собой жидкость черного цвета, а при низком его содержании могут быть пастообразными или густой консистенции. Условная вязкость при $20{ }^{\circ} \mathrm{C}-20-30$ сантистоксов, аминное число - 150-300, $\mathrm{pH}=8 \ldots 12$ и температура вспышки $-90-120^{\circ} \mathrm{C}$.

Кубовые остатки при производстве продукта «Новантокс 8 ПФДА» представляют собой вязкую маслянистую жидкость темно-коричневого цвета с зеленоватым или фиолетовым оттенком следующего состава (приблизительно): «Новантокс 8 ПФДА» - 8,6 \%; свободный $n$-аминодифениламина - 0,54 \%; 2-этилгексановая кислота - 27,0 \%; К-соль 2-этилгексановой кислоты 9,4\%; смолы - остальное.

Согласно Приложению 3 СП 2.1.7.1386-03 («Санитарные правила по определению класса опасности токсичных отходов производства и потребления») асфальтобетонные смеси с использованием продукта «Новантокс 8 ПФДА» и АсД относятся к 4-му классу опасности.

В результате изучения влияния количества вводимых отходов дробления известняков на физико-механические свойства органических бетонов установлено их оптимальное содержание.

С целью установления предельно допустимого уровня старения асфальтобетонов выполнены специальные экспериментальные исследования, позволившие проверить выдвинутую ра- 
бочую гипотезу о возможности ускоренного изучения процессов старения асфальтобетонов путем выдерживания при высоких температурах. Установлено, что чем больше доступа воздуха во внутреннюю структуру асфальтобетонов, чем выше температура в процессе приготовления и эксплуатации и чем интенсивнее действуют на материал подвижные нагрузки и напряжения, тем выше вероятность изменения их свойств. Установлено также, что чем выше температура нагрева при приготовлении и временном хранении битума, тем быстрее он в составе бетонов теряет свои вяжущие свойства со временем [7-10]. При этом выявлено, что старение битума происходит гораздо интенсивнее именно в процессе приготовления, в момент действия высоких температур и нахождения его в пленочном состоянии. Старение битума и асфальтобетонов в конструктивных слоях в процессе эксплуатации в конструктивных слоях дорожной одежды с течением времени замедляется $[11,12]$. При этом замечено, что свойства битума и асфальтобетона в поверхностных слоях, в местах наличия трещин в покрытии и у кромок конструктивных слоев изменяются во времени гораздо быстрее, чем во внутренней структуре асфальтобетонов. Это, видимо, можно объяснить тем, что данные зоны более доступны воздействию кислорода воздуха, солнечной радиации и т.д. Процессы старения асфальтобетона, кроме того, зависят от вида минеральных компонентов и вида вяжущего: в зонах контактов битума с пористыми заполнителями в начальный период вяжущее стареет быстрее, затем этот процесс замедляется, а в зонах контакта битума с плотными минеральными материалами битум во времени стареет сравнительно быстрее [10-12].

Исследованиями Л.Б. Гезенцвея, И.А. Королева и др. $[8,13]$ установлено, что в асфальтобетонах с использованием пористых материалов желательно использовать менее вязкие битумы. Известно также, что в районах с низкими температурами для приготовления асфальтобетонных смесей следует использовать менее вязкие битумы, а в районах с высокими температурами - более вязкие битумы. При этом склонность к старению у асфальтобетонов, приготовленных с использованием окисленных битумов при более высоких температурах, выше, чем у приготовленных с использованием компаундированных битумах. На процессы старения влияют также степень нагрева и продолжительность хранения битумов: чем выше температура хранения, чем выше продолжительность выдерживания их при высоких температурах, тем в большей степени подвергаются изменениям свойства битумов и асфальтобетонов с их использованием.

Анализ опубликованных исследований о работоспособности и долговечности асфальтобетонов различного состава и опыт их использования в различных климатических зонах показывают [10-15], что температурный фактор на всех стадиях жизнедеятельности органических вяжущих и бетонов с их использованием является одним из главных факторов, определяющих интенсивность изменения свойств асфальтобетонов во времени с начала эксплуатации и до предельно допустимых их значений, т.е. в эксплуатационный период. Следовательно, действующая на материал тепловая энергия (температура) является одним из главных параметров, определяющих срок службы и долговечность конструктивного слоя дорожных одежд с их использованием.

Фактическая работоспособность материала в конструктивном слое в рассматриваемом периоде обычно оценивается критическими значениями ключевых характеристик материала, перечень которых и значения обычно включаются в действующие нормативы. Однако при этом следует отметить, что установление долговечности материалов в конструктивном слое через изучение динамики изменения их основных физико-механических свойств - достаточно длительный процесс. Поэтому на кафедре строительных технологий и автомобильных дорог Поволжского государственного технологического университета для этой цели предложена новая методика изучения долговечности и температурной устойчивости конструкционных материалов на основе проведения стандартных лабораторных исследований. Она позволяет проводить оценку работоспособности материалов после действия высоких температур за относительно короткий промежуток времени.

Суть данной методики состоит в тщательном перемешивании при рабочих температурах компонентов смесей изучаемых составов, равномерном разложении их в отдельных поддонах- 
подносах, размещении в сушильный шкаф и выдерживании при расчетной температуре $(+150 \pm 2)^{\circ} \mathrm{C}$ в течение $0,1,2,3,4,5,6,7$ ч.

После истечения каждой стадии прогревания отдельные образцы смесей вынимают из сушильного шкафа, охлаждают до комнатных температур и из них по методике ГОСТ 12801-98* формуют стандартные цилиндрические образцы диаметром и высотой 71,4 мм. Далее образцы подвергаются испытаниям по действующим стандартным методикам и устанавливаются их основные физико-механические свойства. Некоторые результаты этих экспериментов приведены в табл. 1 и на рисунке.

Таблица 1

Значения предела прочности при сжатии при $+50{ }^{\circ} \mathrm{C}$ образцов модифицированных и не модифицированных АБ и ЩМА с ОДИ

\begin{tabular}{|c|c|c|c|c|c|c|}
\hline \multirow{2}{*}{$\begin{array}{c}\text { № } \\
\text { п/п }\end{array}$} & $\begin{array}{c}\text { Время } \\
\text { прогревания } \\
\text { смеси, ч }\end{array}$ & $\begin{array}{c}\text { не модифи- } \\
\text { цированного } \\
\text { АБ с ОДИ }\end{array}$ & $\begin{array}{c}\text { модифицированно- } \\
\text { го АБ с ОДИ } \\
\text { (с добавкой 0,5\%) }\end{array}$ & $\begin{array}{c}\text { АБ класс- } \\
\text { сического } \\
\text { состава }\end{array}$ & $\begin{array}{c}\text { не модифициро- } \\
\text { ванного ЩМА } \\
\text { с ОДИ }\end{array}$ & $\begin{array}{c}\text { модифицированного } \\
\text { ЩМА с ОдИ } \\
\text { (с добавкой 0,5 \%) }\end{array}$ \\
\hline 1 & 0 & 2,3 & 2,6 & 2,1 & 1,65 & 1,65 \\
\hline 2 & 1 & 1,8 & 2,0 & 1,4 & 1,53 & 1,65 \\
\hline 3 & 3 & 1,5 & 1,8 & 1,5 & 1,10 & 1,57 \\
\hline 4 & 5 & 1,3 & 1,5 & 1,4 & 1,03 & 1,37 \\
\hline 5 & 7 & 1,2 & 1,3 & 1,4 & 1,00 & 1,30 \\
\hline
\end{tabular}

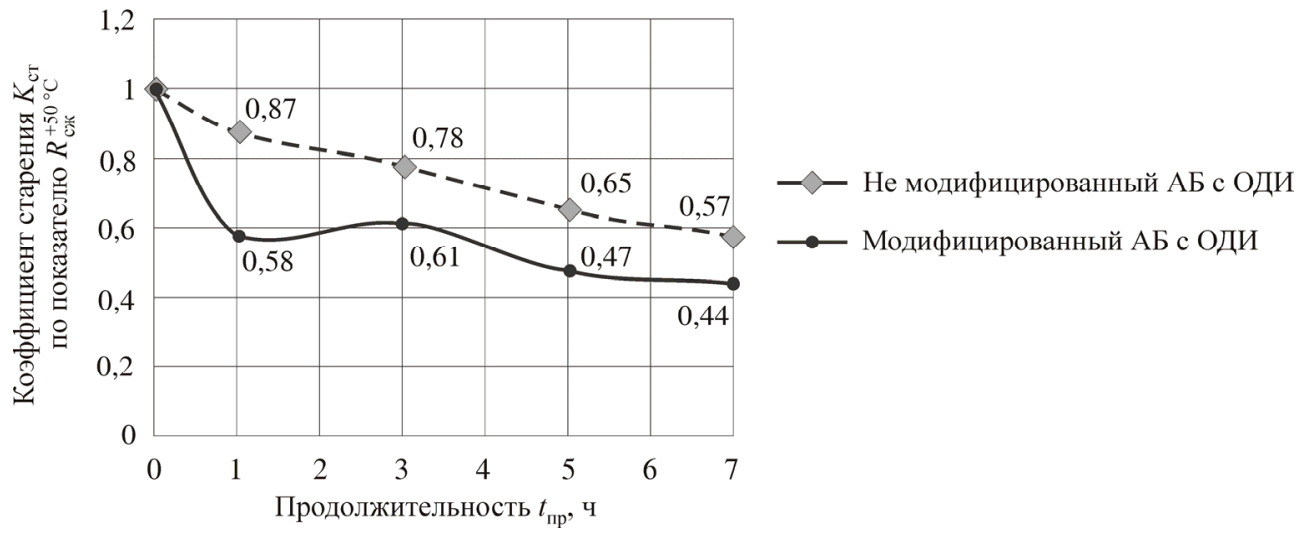

Рис. График зависимости значений коэффициента старения $\left(K_{\mathrm{c \tau}}\right)$ по показателю предела прочности при сжатии при $+50{ }^{\circ} \mathrm{C}$ не модифицированного и модифицированного асфальтобетона с ОДИ типа Б с добавкой АсД в количестве $0,5 \%$ от продолжительности прогревания смеси при $+150{ }^{\circ} \mathrm{C}$

Из проведенных автором и другими учеными исследований известно [10-12, 14], что в результате воздействия высоких температур показатели бетонов с использованием органических вяжущих меняются, как правило, в сторону ухудшения. Анализ результатов данных экспериментов подтвердил, что наибольшим изменениям подвергаются значения предела прочности при сжатии при $+50{ }^{\circ} \mathrm{C}$, т.е. этот показатель является наиболее чувствительным к прогреванию [9]. Далее по результатам экспериментов рассчитываются значения коэффициента старения $\left(K_{\text {ст }}\right)$. Для примера некоторые результаты этого расчета для модифицированного с 0,5 \% (от массы би-

* ГОСТ 12801-98. Материалы на основе органических вяжущих для дорожного и аэродромного строительства. Методы испытаний. Введ. в действие Постановлением Госстроя России 24.11.1998 г., № 16 с 01.01.1998 г. М.: ГУП ЦПП, 1999. 39 с. 
тума БНД 90/130) кубовыми остатками при производстве продукта «Новантокс 8 ПФДА» и не модифицированного ЩМА с ОДИ представлены в табл. 2.

Анализ приведенных в табл. 1, 2 данных показывает, что все исследованные свойства щебеночно-мастичных асфальтобетонов и асфальтобетонов с отходами дробления известняков типа Б по мере увеличения продолжительности прогревания ухудшаются, т.е. эти материалы стареют. Для сравнения в табл. 3 представлены результаты аналогичных расчетов для модифицированного с 0,5 \% (от массы битума БНД 90/130) АсД и не модифицированного асфальтобетона с ОДИ типа Б.

Таблица 2

Значения коэффициента старения ЩМА с ОДИ после прогревания при высокой температуре

\begin{tabular}{|c|c|c|c|c|c|c|c|}
\hline \multirow{2}{*}{$\begin{array}{l}\text { № } \\
\text { п/п }\end{array}$} & \multirow{2}{*}{$\begin{array}{c}\text { Продолжительность } \\
\text { прогревания, ч }\end{array}$} & \multicolumn{6}{|c|}{ Значения коэффициента старения $K_{\text {ст }}$ по показателям } \\
\hline & & $R_{\mathrm{c \%}}^{+20^{\circ} \mathrm{C}}$ & $R_{\mathrm{c} \kappa}^{+50^{\circ} \mathrm{C}}$ & $K_{\text {вод }}$ & $\begin{array}{l}\text { трещино- } \\
\text { стойкости }\end{array}$ & $\begin{array}{c}\text { коэффициента } \\
\text { внутреннего трения }\end{array}$ & $C_{\text {сщ }}$ \\
\hline 1 & 2 & 3 & 4 & 5 & 6 & 7 & 8 \\
\hline \multicolumn{8}{|c|}{ не модифицированный (Б = 7,0 \% от массы минеральной части АБ с ОДИ) } \\
\hline 1 & 0 & 1,00 & 1,00 & 1,00 & 1,00 & 1,00 & 1,00 \\
\hline 2 & 1 & 0,97 & 0,87 & 1,07 & 0,93 & 0,99 & 0,96 \\
\hline 3 & 3 & 0,94 & 0,78 & 1,09 & 0,92 & 0,95 & 0,83 \\
\hline 4 & 5 & 0,90 & 0,65 & 1,06 & 0,89 & 0,94 & 0,76 \\
\hline 5 & 7 & 0,67 & 0,57 & 1,08 & 0,80 & 0,90 & 0,51 \\
\hline \multicolumn{8}{|c|}{ модифичированный (Б = 5,8 \% от массы минеральной части АБ с ОДИ, АсД-0,5 \% от массы битума) } \\
\hline 6 & 0 & 1,00 & 1,00 & 1,00 & 1,00 & 1,00 & 1,00 \\
\hline 7 & 1 & 0,98 & 0,58 & 0,86 & 0,89 & 0,99 & 0,98 \\
\hline 8 & 3 & 1,05 & 0,61 & 1,15 & 0,88 & 0,97 & 0,85 \\
\hline 9 & 5 & 0,79 & 0,47 & 1,023 & 0,85 & 0,95 & 0,78 \\
\hline 10 & 7 & 0,89 & 0,44 & 1,12 & 0,81 & 0,93 & 0,74 \\
\hline
\end{tabular}

Таблица 3

Значения коэффициента старения АБ с ОДИ типа Б

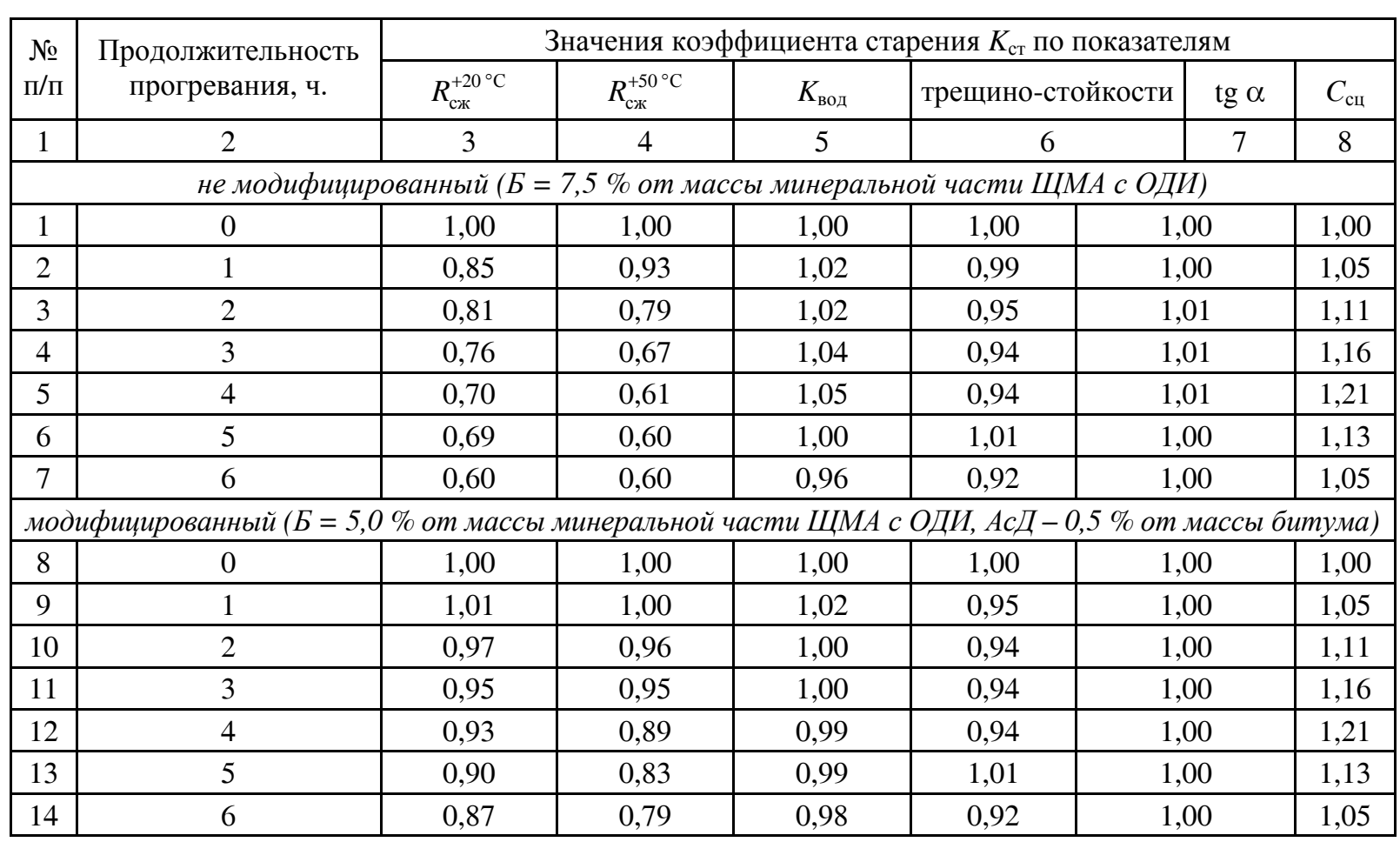


При этом подтвердилось, что наибольшему изменению подвергаются значения предела прочности при сжатии образцов при $+50{ }^{\circ} \mathrm{C}$. Это говорит о том, что их прочность обеспечивается свойствами битумных пленок, которые в этих условиях ускоренно окисляются и полимеризуются. При этом происходит испарение легколетучих составляющих и повышение динамической вязкости битума. Из-за наличия в составе битума и в материалах в целом значительного количества дисперсных частиц эти процессы усиливаются $[13,15]$. Однако одновременно увеличивается хрупкость битумных пленок и по достижении определенных значений их клеящая способность резко снижается. И это проявляется в виде уменьшения сопротивляемости разрушению структуры бетонов под внешними воздействиями (прежде всего, сопротивляемости разрушению при повышенных температурах и растяжению).

Экспериментальные исследования в целом показывают, что при выдерживании образцов щебеночно-мастичного асфальтобетона и асфальтобетона типа Б с отходами дробления известняков в условиях высоких температур $\left(+150^{\circ} \mathrm{C}\right)$ происходит изменение всех физико-механических свойств, как правило, в сторону ухудшения (т.е. старения). Модификация органических бетонов путем введения небольшого количества кубовых остатков при производстве продукта «Новантокс 8 ПФДА» и анилина позволяет несколько повысить их устойчивость к термостарению. Последнее может объясняться тем, что данные кубовые остатки выступают в качестве активирующих веществ: они разжижают первоначальную вязкость битума и способствуют повышению сцепления с поверхностью минеральных зерен, приводят к повышению некоторых физико-механических свойств бетонов, к снижению требуемого количества битума и, как следствие, к их деформационной устойчивости при неблагоприятных условиях.

Для введения модифицирующих добавок в приготовляемые смеси асфальтобетоносмесители должны дооборудоваться емкостью для временного хранения и подогрева их до температур $+50 \ldots 60{ }^{\circ} \mathrm{C}$ и линией для дозировки и подачи их в битумоплавильню или расходную емкость битума.

По выполненной работе в целом можно сделать следующие выводы:

1. Модификация асфальтобетонов с ОДИ типа Б кубовыми остатками при производстве анилина позволяет несколько повысить их устойчивость к термостарению.

2. Термоустойчивость щебеночно-мастичного асфальтобетона с отходами дробления известняков при высокой температуре несколько выше, чем у асфальтобетона с ОДИ типа Б.

3. Термоустойчивость модифицированного кубовыми остатками при производстве продукта «Новантокс 8 ПФДА» щебеночно-мастичного асфальтобетона с отходами дробления известняков несколько выше, чем у модифицированного кубовыми остатками при производстве анилина асфальтобетонов с ОДИ типа Б.

\section{Список литературы}

1. Вайнштейн Е.В. Технология строительства лесовозных дорог из щебеночно-мастичных асфальтобетонов с отсевами дробления известняков: автореф. дис. ... канд. техн. наук. - Йошкар-Ола, 2010. - 16 с.

2. Иливанов В.Ю. Разработка состава и технологий применения модифицированного щебеночно-мастичного асфальтобетона для лесовозных дорог: автореф. дис. ... канд. техн. наук. Йошкар-Ола, 2015. - 18 с.

3. Малянова Л.И. Исследование состава и технологий использования модифицированного асфальтобетона с отходами дробления известняков: автореф. дис. ... канд. техн. наук. - ЙошкарОла, 2016. - 18 c.

4. Иванов Н.Н. Устойчивость асфальтобетонных покрытий при высоких температурах // Труды СоюздорНИИ, вып. 79: Повышение качества асфальтобетона. - М.: СоюздорНИИ, 1975. C. 21-25. 
5. Ядыкина В.В. Управление процессами формирования и качеством строительных композитов с учетом состояния поверхности дисперсного сырья: монография. - М.: Изд-во АСВ, 2009. -374 c.

6. Технические поверхностно-активные вещества из вторичных ресурсов в дорожном строительстве/ под ред. И. В. Королева. - Москва: Транспорт, 1991. - 144c.

7. Скрипкин А.Д., Старков Г.Б., Колесник Д.А. Старение битума в технологическом процессе его подготовки для производства асфальтобетонных смесей // Ежегодная научная сессия Ассоциации исследователей асфальтобетона: сб. ст. и докл. / МАДГТУ (МАДИ). - М., 2010. C. 46-53.

8. Королев И.В. Пути экономии битума в дорожном строительстве. - М.: Транспорт, 1986. -149 c.

9. Рыбьев И.А. Асфальтовые бетоны. - М.: Высш. шк., 1969. - С. 209-245.

10. Кучма М.И. Поверхностно-активные вещества в дорожном строительстве. - М.: Транспорт, 1980. - $191 \mathrm{c}$.

11. Таращанский Е.Г., Вильмсен И.И. Исследование старения асфальтобетона импульсным ультразвуковым методом // Повышение эффективности применения цементных и асфальтовых бетонов в Сибири: сб. 3 / СибАДИ. - Омск, 1975. - С. 40-61.

12. Салихов М.Г., Иливанов В.Ю., Малянова Л.И. Предложение к изучению процессов старения органических бетонов при воздействии высоких температур // Вестник ПГТУ. Серия «Лес. Экология. Природопользование». - 2015. - № 1. - С. 59-65.

13. Дорожный асфальтобетон / Л.Б. Гезенцвей [и др.]; под ред. Л.Б. Гезенцвея. - М.: Транспорт, 1985. - С. 28-29.

14. Калгин Ю.И. Дорожные битумоминеральные материалы на основе модифицированных битумов: моногр. - Воронеж: Изд-во Воронеж. ун-та, 2006. - 271 с.

15. Дорожные битумоминеральные материалы на основе модифицированных битумов (технология, свойства, долговечность): монография / В.Т. Ерофеев, Ю.М. Баженов, Ю.И. Калгин [и др.] / под ред. Ю.М. Баженова, В.Т. Ерофеева. - Саранск: Изд-во Мордов. ун-та, 2009. - 276 с.

\section{References}

1. Vajnshtejn E.V. Tekhnologiya stroitel'stva lesovoznyh dorog iz shchebenochno-mastichnyh asfal'tobetonov s otsevami drobleniya izvestnyakov [Technology of construction of logging roads from crushed stone-mastic asphalt concretes with crushed limestone cuttings]. Abstract of Ph. D. thesis. Joshkar-Ola, 2010, 16 p.

2. Ilivanov V.Yu. Razrabotka sostava i tekhnologij primeneniya modificirovannogo shchebenochno-mastichnogo asfal'tobetona dlya lesovoznyh dorog [Development of the composition and technologies for the use of modified crushed stone-mastic asphalt for timber roads]. Abstract of Ph. D. thesis. Joshkar-Ola, 2010, 18 p.

3. Malyanova L.I. Issledovanie sostava i tekhnologij ispol'zovaniya modificirovannogo asfal'tobetona s othodami drobleniya izvestnyakov [Study of the composition and technologies of using modified asphalt concrete with limestone crushing wastes]. Abstract of Ph. D. thesis. Joshkar-Ola, 2010, 18 p.

4. Ivanov N.N. Ustojchivost' asfal'tobetonnyh pokrytij pri vysokih temperaturah [Stability of asphalt-concrete coatings at high temperatures]. Povyshenie kachestva asfal'tobetona. Moscow, Trudy Sozdor scientific research institute, 1975, vol. 79, pp. 21-25.

5. Yadykina V.V. Upravlenie processami formirovaniya i kachestvom stroitel'nyh kompozitov s uchetom sostoyaniya poverhnosti dispersnogo syr'ya [Management of the processes of formation and quality of building composites, taking into account the state of the surface of dispersed raw materials]. Moscow, Association of Construction Universities, $2009,374 \mathrm{p}$.

6. Tekhnicheskie poverhnostno-aktivnye veshchestva iz vtorichnyh resursov v dorozhnom stroitelstve [Technical surfactants from secondary resources in road construction ]. Ed. I.V. Korolyov. Moscow, Transport, 1991, 144 p.

7. Skripkin A.D., Starkov G.B., Kolesnik D.A. Starenie bituma v tekhnologicheskom processe ego podgotovki dlya proizvodstva asfal'tobetonnyh smesej [Aging of bitumen in the technological process of its preparation for the production of asphalt-concrete mixtures]. Asphalt Association Explorers. Moscow, Moscow Road Institute, 2010, pp. 46-53.

8. Korolev I.V. Puti ehkonomii bituma v dorozhnom stroitel'stve [Ways to save bitumen in road construction]. Moscow, Transport, 1986, $149 \mathrm{p}$.

9. Ryb'ev I.A. Asfal'tovye betony [Asphalt concretes]. Moscow, High school, 1969, pp. 209-245.

10. Kuchma M.I. Poverhnostno-aktivnye veshchestva v dorozhnom stroitel'stve [Surface-active substances in road construction]. Moscow, Transport, 1980, $191 \mathrm{p}$. 
11. Tarashchanskij E.G., Vil'msen I.I. Issledovanie stareniya asfal'tobetona impul'snym ul'trazvukovym metodom [Investigation of aging of asphalt concrete by pulsed ultrasonic method]. Povyshenie ehffektivnosti primeneniya cementnyh $i$ asfal'tovyh betonov v Sibiri, Omsk, Siberian Road Institute, 1975, no 3, pp. 40-61.

12. Salihov M.G., Ilivanov V.Yu., Predlozhenie, Malyanova L.I. Predlozhenie k izucheniyu processov stareniya organicheskih betonov pri vozdejstvii vysokih temperature [Proposal to the study of the aging of organic concretes under the influence of high temperatures]. Vestnik PGTU. Seriya «Les. Ekologiya. Prirodopol'zovanie», 2015, no 1, pp. 59-65.

13. Gezencvej L.B., Gorelyshev N.V., Boguslavskij A.M., Korolev I.V. Dorozhnyj asfal'tobeton [Road asphalt concrete]. Moscow, Transport, 1985, pp. 28-29.

14. Kalgin Yu.I. Dorozhnye bitumomineral'nye materialy na osnove modificirovannyh bitumov [Road bituminous mineral materials based on modified bitumen ]. Voronezh, Voronezh, 2006, $271 \mathrm{p}$.

15. Erofeev T., Bazhenov Yu.M., Kalgin Yu.I. et al. Dorozhnye bitumomineral'nye materialy na osnove modificirovannyh bitumov (tekhnologiya, svojstva, dolgovechnost') [Road bituminous mineral materials based on modified bi-tums (technology, properties, durability]. Saransk, 2009, 276 p.

Получено 01.02.2018

\section{Об авторах}

Салихов Мухаммет Габдулхаевич (Йошкар-Ола, Россия) - доктор технических наук, профессор, профессор кафедры «Строительные технологии и автомобильные дороги» Поволжского государственного технологического университета (424000, г. Йошкар-Ола, пл. Ленина, д. 3, e-mail: SalihovMG@ volgatech.net).

Иливанов Виктор Юрьевич (Чебоксары, Россия) - кандидат технических наук, старший преподаватель Чувашского государственного университета им. И.Н. Ульянова (ЧГУ им. И.Н. Ульянова) (428015, г. Чебоксары, пр. Московский, д. 15, e-mail: ilivanovv@ rambler.ru).

Малянова Лидия Ивановна (Чебоксары, Россия) - кандидат технических наук, доцент кафедры «Строительные дороги и ниженерная экология» Волжского филиала Московского государственного технического университета (МАДИ) (428000, г. Чебоксары, пр. Тракторостроителей, д. 101, корп. 30, e-mail: malyanova.lidia@ mail.ru).

Веюков Евгений Валерианович (Йошкар-Ола, Россия) - кандидат технических наук, доцент кафедры «Строительные технологии и автомобильные дороги» Поволжского государственного технологического университета (424000, г. Йошкар-Ола, Панфилова, 17, e-mail: jenya1060@bk.ru).

\section{About the authors}

Muchammet G. Salichov (Yoshkar-Ola, Russian Federation) - Doctor of Technical Sciences, Professor, Professor Department of Building Tecnology and Automobile Roads, Volga State University of Technology (3, area Lenin, YoshkarOla, 424000, Russian Federation, e-mail: SalihovMG@volgatech.net).

Viktor J. Ilivanov (Cheboksaries, Russian Federation) - Ph.D. in Technical Sciences, Senior Lecturer, Chuvash State University named after I.N. Ulyanov (15, Moscow av., Cheboksary, 428015, Russian Federation, e-mail: ilivanovv@rambler.ru).

Lidia I. Malyanova (Cheboksaries, Russian Federation) - Ph.D. in Technical Sciences, Associate Professor, Volga Branch of Moscow State Automobile and Road Technical University (MADI) (101, korp. 30, Traktorostroiteley pr., Cheboksary, 428015, Russian Federation, e-mail: malyanova.lidia@mail.ru).

Evgeny V. Veyukov (Yoshkar-Ola, Russian Federation) - Ph.D. in Technical Sciences, Associate Professor, Department of Building Tecnology and Automobile Roads, Volga State University of Technology (17, Panfilova st., Yoshkar-Ola, 424000, Russian Federation, e-mail: SalihovMG@volgatech.net). 